\title{
Application of Plant Dyeing Craft in the Design of Modern Residential Products
}

\author{
Yanrui Mou, a , Dan Zhang ${ }^{1}$ \\ ${ }^{1}$ Sichuan Agricultural University, Chengdu, Sichuan Province, China \\ amuyanrui@163.com
}

\begin{abstract}
Keywords: Plant Dyeing, Folk Fine Arts, Household Products, Environmental Protection, Health
\end{abstract} Care.

\begin{abstract}
In 1856, the famous chemist W. H. Pekin successfully created mauveine by synthesis. Since then, humans have entered a new era of synthetic dyes. But recently, people gradually accept the concepts of environmental protection and health preservation, while chemical dyes contain carcinogenic substance and are harmful tothe environment. So nowadays, the traditional plant dyeing craft catches people's attentions and come into our lives again. In daily life, our bodies and skins contact with household products most frequently, so now the industry of household products develops in accordance with the global green trend. Plant dyeing is an outstanding component of Chinese folk fine arts which needs to be inherited and promoted. Textiles dyed by plants have high aesthetic values and a lot of other advantages. They are not only natural and environmental friendly, but also benefit for people's health, since most of the dyeing materials are Chinese herbal medicine. To explore the advantages and features of plant dyeing craft, and apply it to the design of household products, are new development directions of household products design. From the perspectives of aesthetic values, environmental protection and health care, this article analyzes the advantages of plant dyeing craft and its application prospects in household products design .
\end{abstract}

\section{Introduction}

China is rich in cultural resources. For thousands of years, ingenious working people here have created various forms of folk fine arts by using their wisdom and crafts. Folk fine arts include paper cutting, dyeing, embroidery, clay sculpture, New Year painting, shadow puppetry and so on. But nowadays, only a small number of these arts are still being exploited and used. Many traditional elements are not applied to modern household products design. These traditional skills, however, can be used to support the production of products, and are worthy of studying and inheriting. In the field of folk fine arts, traditional dyeing is an important part with a long history. The development of dyeing is the result of human society's development and human's interactions with natural environment. It can be said that, dyeing craft is a typical representative of a nation's production industry, as well as the most complete and specific medium which can fully reflect our national characteristics.[1] What's more, dyeing industry directly promote the development of clothing and textile industries. Today, with the highly developed industrializing, science and technology are making continuous progresses; new materials are constantly emerging. How to inherit and develop the essence of excellent folk fine arts, and how to apply traditional plant dyeing craft to modern household products design? Relevant practitioners need to consider these questions carefully. Meanwhile, the inheritance and development of folk fine arts are conducive to the national development of modern design, and can also provide a living source for modern design. It can help modern design to become a more dynamic industry with more national characteristics.

\section{The Application History of Plant Dyeing Craft in Household Products}

"Plant Dyeing" is a method of dyeing textiles with natural plant dyes. Archaeological discoveries show that in the primitive Neolithic era, people began to dye materials with natural pigment. Although these behaviors originated from primitive witchcraft rituals, they could prove that primitive people had paid attention to the dyeing abilities of natural materials. According to historical records, 
in the early period of Yellow Emperor, our ancestors found that plant roots, stems, leaves and barks can be used to extract color. Then they began to dye cloths and make clothes by using plant sap. This is the earliest historical record of plant dyeing in China, and the earliest dyeing behaviors out of aesthetic demands. Through continuous explorations and practices, people in Zhou Dynasty mastered skills of plant dyeing. The quantity and species of plant dyes reached certain scales. Officials specialize in plant dyes management also merged to collect plant dyes for the purpose of dyeing clothes. In Qin and Han Dynasties, plant dyes became the mainstream of textile dyeing, and formed distinctive styles. Tang Dynasty was the heyday of plant dyeing craft. Bright and colorful silk in China was exported to western countries through the Silk Road, which promoted the trade and cultural exchange between the East and the West. In Song Dynasty, many plant dyeing skills were invented. In Ming and Qing Dynasties, more plants were used as dyeing materials. Domestic plant dyes could be self-sufficient. Meanwhile, a considerable number of plant dyes were exported to other countries. A large number of red cottons, which were made from red flowers, were exported to Japan. According to relevant records, techniques of dye plants cultivation, application and preparation reached the peaks. Dye houses also developed greatly. In Shuo Wen Jie Zi, the Chinese dictionary in Eastern Han Dynasty, 39 kinds of color were titled. While in Ming Dynasty, Tian Gong Kai Wu, the craft encyclopedia of China and Tian Shui Bing Shan Lu, which recorded the family property of a high-ranking official, recorded 57 kinds of color names. In Qing Dynasty, The Principles and Stitchings of Chinese Embroidery recorded 704 kinds of color names totally. [2] With the continuous development of plant dyeing skills, some textiles were manufactured by using plant dyeing craft. These colorful textiles were used in ancient beddings, pillows, curtains and other household products. However, with the development of modern industry, the traditional plant dyeing technique once declined. From the late Qing Dynasty to the Republic of China, foreign raw materials and mechanical equipment flew into Chinese market. The development space of traditional plant dyeing industry was squeezed. Chinese traditional plant dyeing craft began to decline. Since the Emperor Qianlong, Chinese people began to learn form the west. Western commodities were introduced to China, too. In the late Qing Dynasty, Chinese clothing industry changed greatly. In the Republic of China era, a large number of mechanical equipment was introduced, and the traditional handicraft was affected. Almost all kinds of industries in our country were influenced greatly by western technology. The trend of advocating "new styles" and "western styles" also led to the decline of plant dyeing technique. At the same time, chemical dyes began to flow into China, and were used in the dyeing process gradually. These foreign raw materials and mechanical preparation skills were low cost and fast speed, so they were being used in the dyeing process rapidly. These materials and equipment directly impacted the development of traditional plant printing and dyeing craft.

With the continuous improvement of people's material life, in today's society, people begin to notice and understand the traditional plant dyeing technique again. The technique has achieved considerable development fruits, and gained popularity from increasing number of people.

\section{The Current Situation of Application of Plant Dyeing Craft in Modern Residential Products Design}

In 1856, the famous chemist W. H. Pekin successfully produced mauveine through chemical synthesis. Since then, people have entered a new era of synthetic dyes. But in recent years, people gradually accept the concepts of environmental protection and health preservation. Chemical dyes contain carcinogenic substance and damage the environment. So nowadays, plant dyeing technique catches people's attentions and come into our lives again. Technical practitioners from many countries begin to explore plant dyes to meet people's requirements for natural and healthy life. For example, Indian researchers extract plant dyes from Aspen treebarks and balsamine flowers. They use apricot leaves to dye yarn textiles, Babool barks to dye nylon textiles, and tea to wool textiles. [3] Japan researchers set up specialized research institutes to study plant dyes. They use modern science and technology to develop plant dyes from euphorbia. Huangli Company realized the mass production of plant dyes of brown, green and blue colors. Then, these three kinds of color were used to create more colors. Dahe Dyeing Company creates the "grass clothing dyeing", while Xingran 
Company launches "indigo printing" skills. [4] In the world, plant dyeing craft is combined with popular culture, and applied into clothing design. For example, in the BUAISOU dyeing workshop founded by Japanese designer Kenta Watanabe, isatis roots become dyeing materials. After processing, these roots become blue dyes and are used in T-shirts and jeans. These clothes are very popular in the United States. In 2014, through the introduction of an American gallery which sells hand made products, BUAISOU successfully landed in New York and opened a workshop in Broolyn. Many international media reported that event.

In recent years, many Chinese research institutes, like the Beijing Institute of Clothing Technology, the Ecological Textile Laboratory in Jiangnan University and Suzhou University, also set about studying plant dyes. Now, domestic researches on plant dyeing mainly focus on the crafts, aesthetics values, histories and development prospects of plant dyeing technique. Researches on the application of plant dyeing craft into household productions design are rare to be seen. At present, only ethnic minorities in remote mountainous areas still use traditional plant dyeing skills to make household products. Dali is an autonomous prefecture of the Bai nationality in Yunnan province. People here still use ancient skills to produce indigo blue dyes. Tibetan carpets, the household products which can be found only in Tibetan, have a history of 600 years. They are dyed by natural plants, too. In Miao areas in Guizhou province, indigo powders are still used extensively to make batiks. In online shopping platforms, a small amount of plant dyeing lovers sale their handmade products. Plant dyeing enthusiasts can be found everywhere. Many museums of plant dyeing experience are established to simulate the plant dyeing processes of bandhnu and battik. Mostly experts believe that, as one of the traditional Chinese crafts, plant dyeing craft has considerable values and advantages, and is worthy of promoting and inheriting. Today, people pursue natural things and environmental protection, so the technique of plant dyeing would have a bright development prospect. Actively promoting and applying of plant dyeing technique are conducive to opening up new paths for products design, and are helpful to the promotion and inheriting of traditional cultures.

\section{The Development Directions of Application of Plant Dyeing Craft in Modern Residential Products}

Inherit related skills: to combine traditional aesthetic values with household products design. With the highly developed industrializing, fewer people want to learn traditional Chinese crafts and aesthetics now. Some crafts gradually decline and disappear. The author holds that, Chinese should keep the belief of inheriting and carrying forward traditional skills and cultures. At present, most of the household products in markets are dyed by chemical dyes. Design patterns are basically the current popular models in bright colors. These products are easy to become outdated and cause aesthetic fatigue. Plant dyeing craft, on the contrary, is the traditional plant dyeing craft in China. The patterns and colors of plant dyeing textiles have very high aesthetic values. These textiles can offer people the visual enjoyment of natural beauty, and the sincere feelings of Chinese folk arts. From the perspective of design patterns, the materials of plant dyes derive from natural plants. Plant dyeing has various designing topics, such as flowers, birds, fish, insects, geometric patterns and letters.Plant dyeing also has a lot of themes, which usually reflect people's pursuit of auspiciousness. These patterns are fresh, simple and pure. They can meet people's psychological needs of pursuing pure and nature. From the perspective of colors, plant dyeing textiles have elegant colors with low saturation. These colors cannot easily become outdated. The color of gray is used most frequently. It can help people to feel ethereal, profound and elegant. Combining plant dyeing with household products design can help people who live in hustle and bustle cities to return to nature, and bring peace to their minds. What's more, plant dyes are easy to find and obtain. Now some commonly used plant dyeing materials are onionskin, tea, chestnut shells and hematoxylin. They are easy to access and extract. Traditional printing skills like bandhnu and batik can be applied to modern household products design. The combination has good development prospects.

Health care: to combine the health benefits of plans with household products design. Many materials for plant dyeing are Chinese herbal medicine. They care good for people's health. The health functions of dyeing materials are key to plant dyeing. Isatis roots which are used in Aizen can 
disinfect infections, relieve internal heat or fever, reduce swelling and stop bleeding. Hematoxylin which can dye red color is a commonly used Chinese medicine in promoting blood circulation, removing blood stasis, relieving swellings and pains. Lithospermum has functions of bacteria resistance and bacteriostasis, detoxication and promoting eruption. Semen cassiae can clear away the liver-fire and eliminate winddamp. Pomegranate peel has antibacteria function, while coptis can clear heat. Other dye plants like gallnut, safflower, onion and wormwood are also commonly used in folk medicine. These plants can be used as dyes and medicine. So the textiles which are dyed by these plants can have special effects of sterilization, prevent skin diseases, snakes and insects, and refresh oneself. [5]To combine these characteristics with household product design, we can realize the combination of household products with health care to a certain extent. At present, people pay their attentions on health care and environmental protection. These health care concepts are good starting points for product design. They are conducive to the development and selling of products. At the same time, the combination goes in accordance with the concept of "heaven-man unity".

Environmental protection: to combine the concept of environmental protection with household products design. At present, the international community continuously advocates the idea of sustainable development. The raw materials of plant dyeing technique are natural plants. The production of dyes is the extraction of pigments from plants. That process produces no pollution, and the main components of dyes are the same as plants. Thus, the residues of these dyes can decompose easily, and do not harmful to ecological environment. After proper treatments, these residues can even become good fertilizers. Hence, the development of plant dying technique response to the call of sustainable development of the government, and conform to the environmental protection requirements of contemporary product design trends. So the application prospects of plant dyeing technique are bright.

\section{Conclusions}

In everyday life, our bodies and skins contact with household products frequently. Thus, with the increasing of people's material and cultural needs, household products industry needs to lay emphases on the plant dyeing craft. Traditional plant dyeing craft use dyes and cloths which are made from natural plants, so it is environmental friendly and good for health. Its security and biomedicine brings high values of environmental protection. Plant dyes without harmful dyeing agents have the following advantages. Firstly, they do not produce adverse effects on human body. Secondly, the raw materials are renewable and can be recycled. Thirdly, the production process of dyes does not pollute the environment. So plant dyes are green household products which do not damage human health. They can meet people's requirements on household products at the present stage. Moreover, with the continuous exploration and implementation of traditional crafts, as well as the continuous improvement of non-material cultural heritage protection policies, the traditional plant dyeing technique can be combined with household products design to help contemporary people to understand Chinese folk arts better, and to inherit and carry forward excellent Chinese traditional crafts. Therefore, the application of plant dyeing craft in modern household products design has broad development spaces and great significance.

\section{References}

[1] W. Wang, An overview on the development history of traditional Chinese plant dyeing craft, J. Sichuan Silk. 3 (2007) 53.

[2] Information on http://baike.baidu.com

[3] H.F. Zhang, The application statuses and development prospects of two kinds of natural plant dyes, J. Progress in Textile Science and Technology. 2013.

[4] B.Y. Zhao, Researches and analyses of plant dye curcuma domestica valet, J. Journal of Zhejiang Textile and Fashion vocational College. 2011. 
[5] Y.T. Huang, Preliminary study on the application of plant dyes with medicinal values and health functions in clothing, J. Popular Literature and Art. 2014. 